\title{
Genetic variation of isolated Picea balfouriana populations from the southeast of the Qinghai-Tibet Plateau
}

\author{
Zhuoxuan $\mathrm{LU}^{1,2}$, Yuhua WANG ${ }^{1}$, Xiaolu ZHANG ${ }^{1}$, Helena KoRPELAINEN ${ }^{3}$, Chunyang LI ${ }^{1 *}$ \\ ${ }^{1}$ Chengdu Institute of Biology, Chinese Academy of Sciences, P.O. Box 416, 610041 Chengdu, P.R. China \\ ${ }^{2}$ Graduate School of the Chinese Academy of Sciences, 100039 Beijing, P.R. China \\ ${ }^{3}$ Department of Applied Biology, P.O. Box 27, 00014 University of Helsinki, Finland
}

(Received 22 February 2008; revised version 11 September 2008; accepted 30 January 2009)

\author{
Keywords: \\ conifer / \\ SSR / \\ STS / \\ genetic differentiation / \\ Bayesian assignment methods
}

\begin{abstract}
- The objective of this work is to estimate the level of genetic variation and pattern of genetic structure of isolated Picea balfouriana populations.

- Nine SSR markers and six STS markers were assayed in ten natural populations of P. balfouriana, which is a regionally distributed conifer species in the southeast of the Qinghai-Tibet Plateau.

- Expected heterozygosity ranged from 0.592 to 0.710 based on SSRs, and from 0.489 to 0.635 based on STS markers. The SSR and STS markers revealed that $11 \%$ and $12 \%$ of variation, respectively, was present among populations. However, the SSRs showed no deviation from the Hardy-Weinberg equilibrium $\left(F_{\mathrm{IS}}=-0.030\right)$, unlike the STS markers $\left(F_{\mathrm{IS}}=0.249\right)$. In addition, assignment methods showed that individuals from the same sampling site usually cluster together.

- Our results indicated that the distribution of genetic variation and population genetic structure of $P$. balfouriana may be attributed to habitat fragmentation and heterogeneous environments caused by the complex topographic environment in the Qinghai-Tibet Plateau. The population genetic information obtained in our study will benefit the development and utilization of appropriate conservation and breeding strategies for $P$. balfouriana.
\end{abstract}

Résumé - Variation génétique des populations isolées de Picea balfouriana du sud-est du plateau Qinghai-Tibet.

- L'objectif de ce travail a été d'estimer le niveau de variation génétique et le modèle de la structure génétique de populations isolées de Picea balfouriana.

- Neuf marqueurs SSR et six marqueurs STS ont été testés sur dix populations naturelles de P. balfouriana qui est un conifère distribué au niveau régional dans le sud-est du plateau Qinghai-Tibet.

- L'hétérozygotie attendue allait de 0,592 à 0,710 sur la base des marqueurs SSR, et de 0,489 à 0,635 sur la base des marqueurs STS. Les marqueurs SSR et STS ont révélé que $11 \%$ et $12 \%$ de la variation, respectivement, étaient présentes parmi les populations. Toutefois, les marqueurs SSR ne montraient aucun écart par rapport à l'équilibre de Hardy-Weinberg $\left(F_{\mathrm{I}}=-0,030\right)$ à la différence des marqueurs STS $\left(F_{\mathrm{I}}=0,249\right)$.Les méthodes d'assignation bayésiennes ont montré que les individus d'un même site d'échantillonnage étaient habituellement groupés ensemble.

- Nos résultats pourraient indiquer que la distribution de la variation génétique et la structure génétique de la population de Pinus balfouriana peuvent être attribuées à la fragmentation de l'habitat et à des environnements hétérogènes causés par un environnement topographique complexe dans le sud-est du plateau Qinghai-Tibet. L'information génétique obtenue sur la population dans notre étude sera bénéfique pour le développement et l'utilisation appropriés des stratégies de conservation et de sélection de Pinus balfouriana.

\section{INTRODUCTION}

The Qinghai-Tibetan Plateau is the highest and largest plateau in the world, and it has experienced a perplexing history of geological events and environmental fluctuations (Liu

\footnotetext{
* Corresponding author: licy@ cib.ac.cn
}

et al., 2006; Zhang et al., 2005). The Hengduan Mountains are located in the southeast of the Qinghai-Tibet Plateau and extend from northwestern Yunnan, through western Sichuan and eastern Tibet, to southern Qinghai. Due to the extremely complex topography and climatic conditions, the Hengduan Mountains have the highest species richness in the area and they are widely regarded as a core region of the Himalayas, 
which is one of the world's biodiversity hotspots (Myers et al., 2000). China is considered to have a high diversity of spruce species, with 16 species and 9 varieties of spruce, and, furthermore, 11 species and 6 varieties being endemic (Ying, 1989). Because 9 species and 5 varieties of spruce have been recorded in the southeast of the Qinghai-Tibet Plateau alone, this region is regarded as the center of the natural range for the genus Picea in China (Yuan et al., 2007).

Picea balfouriana is one of the regionally distributed conifer species in the southeast of the Qinghai-Tibet Plateau and considered as a constructive species within its distribution area (Collaborating Group for Vegetation of Sichuan, 1980). There is a long-standing dispute about the taxonomic status of P. balfouriana. Although it is usually considered as a variety of P. likiangensis (ECCAS, 1978), some botanists consider that $P$. balfouriana should be considered as an independent species, as many differences in geographical distribution and ecological characteristics exist between $P$. balfouriana and P. likiangensis (Editorial committee of the Sichuan Flora, 1983). In China, $P$. balfouriana has a large distribution region, which is inferior only to that of $P$. wilsonii Mast and $P$. brachytyla var. complanata (Liu et al., 2002). It occurs in the western part of the Sichuan province, eastern Tibet and southern part of the Qinghai province. The distribution center of $P$. balfouriana is located in the middle reaches of the Yalong River (Editorial Committee of the Sichuan Flora, 1983). Its vertical distribution mainly ranges from an altitude of 3000 to $4100 \mathrm{~m}$, some trees even occurring at above $4300 \mathrm{~m}$ (Yuan et al., 2007). It is an optimal species for the production of biomass used as a source of, e.g., fuel, fiber and lumber (ECCAS, 1978; Editorial Committee of the Sichuan Flora, 1983). Moreover, it is well adapted to stressful environments at high altitude, especially to cold and drought conditions, which are generally harsh for other trees (Editorial Committee of the Sichuan Flora, 1983). In alpine regions, $P$. balfouriana can form patchy forests, which effectively prevent meadows from expanding and improve the efficiency of water resource conservation (Editorial Committee of Forest of China, 1999). Owing to the above reasons, $P$. balfouriana plays a significant role in the alpine regions. Therefore, the conservation and maintenance of the P. balfouriana populations is an important objective. Better knowledge of the level and distribution of genetic diversity enables the development and utilization of appropriate conservation and breeding strategies. However, so far, no published genetic information of $P$. balfouriana based on molecular markers has been available. In-depth investigations of the genetic diversity and population characteristics within its native range are greatly needed.

Studies on genetic diversity based on molecular markers have the potential to provide information with crucial implications for evolutionary biology and ecology as well as for conservation biology. Microsatellite markers (SSR), which are short tandem repeats, mutate frequently by slippage and proofreading errors during DNA replication (reviewed, e.g., by Oliveira et al., 2006). It follows that SSR markers are highly variable with multiple co-dominant alleles, and they have emerged as the most popular and versatile marker type for ecological applications at present (Li et al., 2002; Rajora et al., 2000; Selkoe and Toonen, 2006). Another marker type, sequence tagged site markers (STS), represents the amplification of well-characterized specific loci and reveal co-dominant polymorphisms (Bouillé and Bousquet, 2005).

In our study, two types of molecular markers (SSR and STS) were used to estimate the genetic structure of $P$. balfouriana populations originating from the southeast of the Qinghai-Tibet Plateau with varying climatic and geographical conditions. The results will not only provide a deep insight into its genetic diversity and population genetic structure but also valuable information for further management and breeding programs of $P$. balfouriana.

\section{MATERIALS AND METHODS}

The distribution of $P$. balfouriana is discontinuous and patchy throughout the southeastern region of the Qinghai-Tibet Plateau. Ten $P$. balfouriana populations, which occur in various natural habitats with different climates and topographies within the major distribution area, were selected for the study (Fig. 1 and Tab. I). All populations were sampled from natural forests occupying an area above $10 \mathrm{hm}^{2}$ and isolated by mountains and rivers. Mature cones were collected from approximately 28 nonadjacent individuals in each population. Sampled trees were separated by a minimum of $50 \mathrm{~m}$. DNA was extracted from megagametophytes using Gen EluteTM Plant Genomic DNA Miniprep Kits (Sigma). About 60 to 90 megagametophytes per tree were pooled to obtain enough DNA. DNA concentrations were determined by comparison with a serial dilution of standard lambda DNA. The quality of DNA was checked by a DNA-Protein instrument (Bio-RAD).

From a set of SSR markers previously developed for a genetic study in Picea species (Pfeiffer et al., 1997; Scotti et al., 2002a, 2002b), six dinucleotide microsatellites (SpAC1F7, EAC7B09, EAC1D10, EAC1F04, EAC6B01 and EAC7H07) and three trinucleotide microsatellites (EATC1B02, EATC1E03 and EATC3G04) were selected. The SSR reactions were based on the procedure described by Scotti et al. (2002b) with some slight modifications. Each amplification reaction was performed in a volume of $25 \mu \mathrm{L}$ containing $2.5 \mu \mathrm{L} 10 \times$ reaction buffer (TaKaRa, Dalian, $\mathrm{Mg}^{2+}$ free Dalian), 1.5-2.5 mM $\mathrm{Mg}^{2+}$ (TaKaRa, Dalian), $150 \mu \mathrm{M}$ dNTP (Promega), $0.25 \mu \mathrm{M}$ primer, $1.0 \mathrm{U}$ Taq polymerase (TaKaRa, Dalian) and 20-40 ng of genomic DNA. The reaction mixtures were overlaid with mineral oil. For each primer, amplifications were carried out in 48-well plates using the following program: an initial step of 4 min at $94{ }^{\circ} \mathrm{C}, 7$ cycles of touchdown consisting of $94{ }^{\circ} \mathrm{C}$ for $30 \mathrm{~s},\left(T_{\mathrm{a}}+7\right){ }^{\circ} \mathrm{C}$ for $30 \mathrm{~s} \Delta \downarrow$ and $72{ }^{\circ} \mathrm{C}$ for $30 \mathrm{~s}, 30$ cycles of amplification consisting of $94{ }^{\circ} \mathrm{C}$ for $45 \mathrm{~s}, T_{\mathrm{a}}$ for $45 \mathrm{~s}, 72{ }^{\circ} \mathrm{C}$ for $45 \mathrm{~s}$, and a final extension of $72{ }^{\circ} \mathrm{C}$ for $10 \mathrm{~min}$. Following electrophoresis, the gels were silverstained using the procedure of Panaud et al. (1996) and photographed using the Gel Doc $2000^{\mathrm{TM}}$ image analysis system (Bio-RAD) following the manufacturer's instructions. To ensure the validity of the analyses, the PCR reactions were performed at least twice in all cases. The fragment sizes were estimated using a standard molecular weight marker pUC 19 DNA / Msp (Hpa).

Six STS primer pairs (Sb17, Sb21, Sb29, Sb32, Sb49 and Sb62) developed for $P$. mariana and previously characterized in $P$. glauca and $P$. sitchensis (Perry and Bousquet, 1998a; 1998b) were used. The amplification program was as follows: an initial step of $5 \mathrm{~min}$ at $94{ }^{\circ} \mathrm{C}, 38$ cycles of $45 \mathrm{~s}$ at $94{ }^{\circ} \mathrm{C}, 45 \mathrm{~s}$ at $50-56{ }^{\circ} \mathrm{C}$ and $90 \mathrm{~s}$ at 


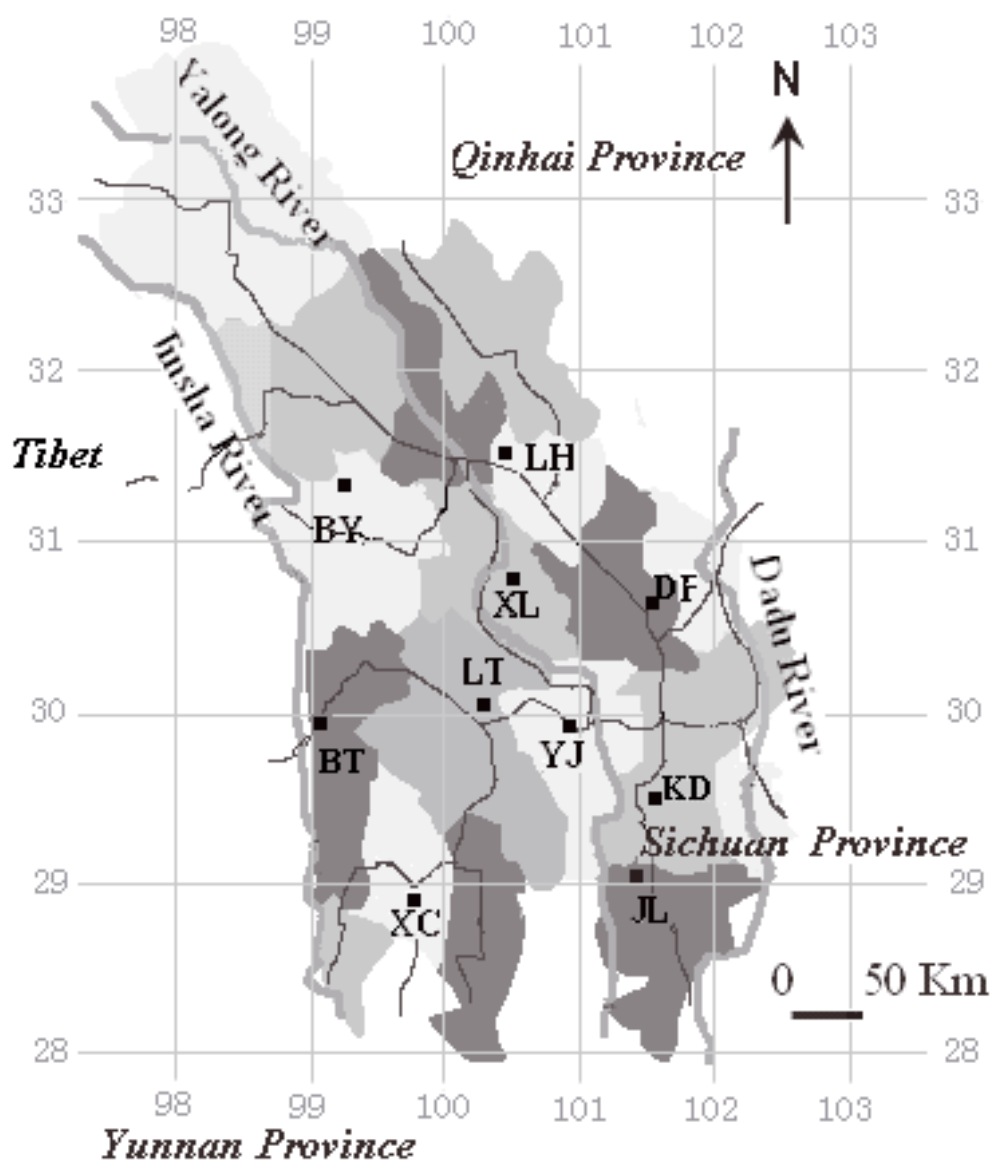

Figure 1. The locations of the ten P. balfouriana populations from the southeast of the Qinghai-Tibet plateau. Different gray shades and lines stand for the territorial districts of local counties of selected populations and main roads.

Table I. The ecological and geographical parameters of the P. balfouriana populations sampled.

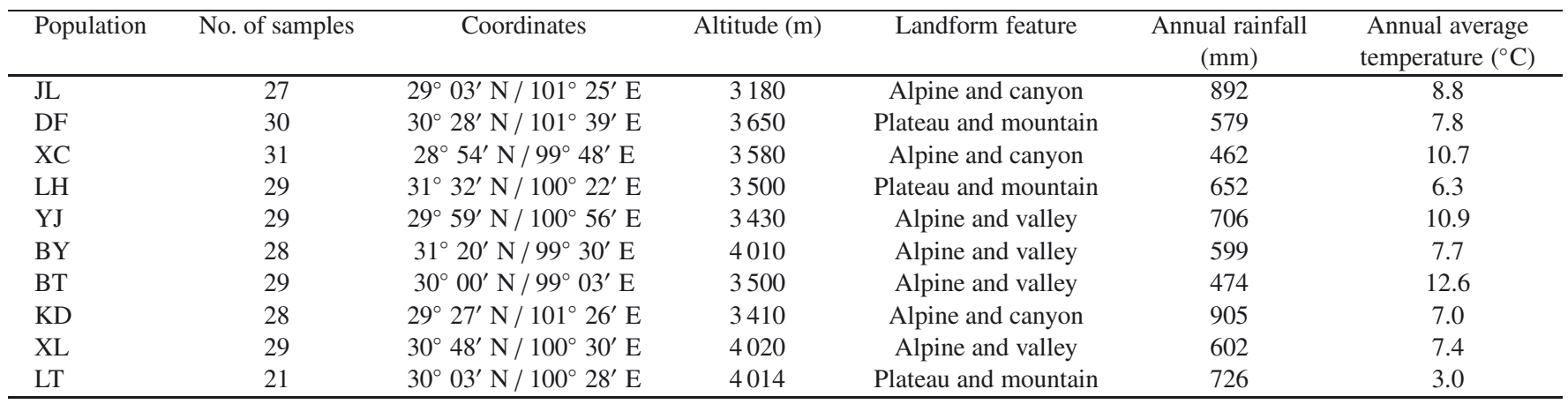

$72{ }^{\circ} \mathrm{C}$, and a final extension step of $7 \mathrm{~min}$ at $72{ }^{\circ} \mathrm{C}$. The PCR products were resolved by electrophoresis on $2 \%$ agarose gels and stained with $0.1 \%$ ethidium bromide. The molecular weights were estimated using the GeneRuler ${ }^{\mathrm{TM}} 100$ bp DNA Ladder Plus (Fermentas). The gel images were recorded and the band sizes were quantified using the Gel Doc $2000^{\mathrm{TM}}$ image analysis system (Bio-RAD).

Observed and expected heterozygosity $\left(H_{\mathrm{o}}\right.$ and $\left.H_{\mathrm{e}}\right)$ at each locus for all populations were estimated by using the program ARLEQUIN (3.11) (Excoffier et al., 2005). GENEPOP version 3.4 (Raymond and
Rousset, 1995) was used to estimate the $p$-values for the exact tests of departures from the Hardy-Weinberg equilibrium using the Markov chain method with 1000 iterations (Guo and Thompson, 1992), and the significance level of each test was determined by applying the sequential Bonferroni procedure (Hochberg, 1988). Null alleles may lead to heterozygote deficiencies. Therefore, the proportion of null alleles was calculated as $\left(H_{\mathrm{e}}-H_{\mathrm{o}}\right) /\left(1+H_{\mathrm{e}}\right)$ (Brookfield, 1996). Genetic divergence between populations was investigated using the estimator $F_{\text {ST }}$ (Weir and Cockerham, 1984). Statistical significance of pairwise 
$F_{\text {ST }}$ values was tested using the program FSTAT 2.9.3 (Goudet, 2001) after the calculation of Bonferroni corrections (Rice, 1989). The analysis of molecular variance (AMOVA) was performed to estimate the relative magnitude of genetic differentiation among populations using the program GenAlEx version 6 (Peakall and Smouse, 2006). The number of effective migrants (Nm) was estimated by Wright's (1969) $0.25\left(1-F_{\mathrm{ST}}\right) / F_{\mathrm{ST}}$. UPGMA clustering was based on Nei's (1972) standard genetic distance. Bootstrapping across loci (1000 replicates) was conducted using Populations 1.2.28 (Olivier, 2002) and visualized using TreeView (Page, 1996). A principal coordinate analysis (PCA) based on Nei's (1972) genetic distance matrices was applied to obtain an additional representation of genetic relationships among populations using the program GenAlEx version 6. Mantel (1967) tests were conducted to investigate the possible relationship between the genetic and geographical distances. A Bayesian cluster analysis was performed using the Structure 2.2 software (Falush et al., 2003; Pritchard et al., 2000), which applies an approach to assign individuals into their populations based on a Markov chain Monte Carlo (MCMC) algorithm. We analyzed the data using a "linkage model", except for one SSR locus (EATC3G04, for which there is no linkage information). The data of genetic map distances between markers came from Acheré et al. (2004) and Pelgas et al. (2006). We analyzed data by a run consisting of 100000 burn-in iterations followed by 500000 further iterations without phased information. Twenty runs were carried out for each $K$ value from 1 to 13, suggested by Evanno et al. (2005).

\section{RESULTS}

Nine SSR markers and six STS markers were used to characterize genetic diversity in ten populations of $P$. balfouriana. As a result of the SSR genotyping, a total of 106 alleles was detected. The number of alleles per locus across all populations ranged from 4 (locus EATC3G04) to 16 (loci SpAC1F7 and EAC1F04), with the mean number of alleles per locus equaling 11.8. Among the SSR loci, 82 alleles were detected across the six dinucleotide microsatellites with the average number of alleles per locus equaling 13.7, and 24 alleles were detected across the three trinucleotide microsatellites with the average number of alleles per locus equaling 8.0 (Tab. II). In the STS genotyping, the number of detected alleles per locus across all populations varied from 6 (Sb29) to 16 (Sb17), with a total of 60 distinct alleles and the mean number per locus equaling 10.0 (Tab. III).

Based on the SSR markers, the average $H_{\mathrm{e}}$ values of individual populations showed a relatively narrow range, with the values varying from 0.592 in population $\mathrm{XC}$ to 0.710 in population BT (Tab. II). Across all populations, the mean expected heterozygosity $\left(H_{\mathrm{e}}\right)$ was 0.631 , with the $H_{\mathrm{e}}$ values ranging from 0.068 at locus EATC3G04 in population LH to 0.909 at locus SpAC1F7 in population XC. When the nine SSR loci were classified into two classes, the dinucleotide microsatellites showed $H_{\mathrm{e}}$ values varying from 0.681 to 0.852 , the average value equaling 0.752 , while the trinucleotide microsatellites possessed lower values, the average equaling 0.416. Based on the STS markers, the average $H_{\mathrm{e}}$ values of individual populations varied from 0.489 in population
DF to 0.635 in population BT (Tab. III). Across all populations, the mean value of $H_{\mathrm{e}}$ was 0.553 , with the individual $H_{\mathrm{e}}$ values varying from 0 at locus $\mathrm{Sb} 21$ in populations $\mathrm{LH}$ and $\mathrm{LT}$ to 0.887 at locus $\mathrm{Sb} 17$ in population XL.

The Hardy-Weinberg equilibrium was verified for all loci and populations by testing the departure of $F_{\text {IS }}$ from zero. Based on the SSR markers, all loci, except for EATC1B02, exhibited significant deviations. Four loci (EATC3G04, EAC7H07, EAC7B09 and SpAC1F7) deviating from the Hardy-Weinberg equilibrium were associated with positive values of $F_{\mathrm{IS}}$, while another four loci (EAC1F04, EAC6B01, EATC1E03 and EAC1D10) were associated with negative $F_{\text {IS }}$ values. Based on the STS genotyping, all six loci significantly departed from the Hardy-Weinberg equilibrium and mostly expressed positive $F_{\text {IS }}$ values. When calculated across all populations, the mean $F_{\text {IS }}$ value based on the SSR loci equaled 0.030 , while the mean value based on the STS loci equaled 0.249 , indicating a deficiency of heterozygosity. In addition, the proportion of null alleles was calculated. Among all loci, only one SSR locus (EAC7B09) showed a positive value equaling 0.055 but four STS loci (Sb21, Sb32, Sb49 and Sb62) presented positive values equaling $0.117,0.126,0.0167$ and 0.163 , respectively.

The genetic divergence among populations was measured by the $F_{\mathrm{ST}}$ estimator (Tab. IV). Based on the SSR markers, the maximum $F_{\mathrm{ST}}$ value was found between populations BY and $\mathrm{DF}\left(F_{\mathrm{ST}}=0.197\right)$, while the minimum $F_{\mathrm{ST}}$ value was found between populations BT and $\mathrm{KD}\left(F_{\mathrm{ST}}=0.044\right)$. Based on the STS markers, the maximum and minimum genetic divergences were observed between the same population pairs as based on the SSR markers, with $F_{\text {ST }}$ values equaling 0.217 and 0.004 , respectively. The Mantel test between the two matrices of $F_{\mathrm{ST}}$ values based on SSR and STS markers showed a significant positive association $(r=0.468, P<0.05)$. The analysis of molecular variance (AMOVA) showed that $11 \%$ and $12 \%$ of the total variation existed among the populations as detected by using SSR and STS markers, respectively. The overall gene flow $(\mathrm{Nm})$ obtained from $F_{\text {ST }}$ based on SSR and STS markers equaled 1.97 and 1.96 , respectively.

The UPGMA dendrograms based on Nei's (1972) standard genetic distances between populations are shown in Figure 2. The SSR dendrogram showed that the main split is between population BY and the rest of the samples. Within the main group, there are three significant sub-groups (populations JL and YJ, BT and KD, and DF and LH) (Fig. 2a). The UPGMA dendrogram based on STS markers showed a similar trend between population BY and other populations, but the subgroups do not follow an identical pattern (Fig. 2b). Remarkably, the UPGMA cluster analyses, based on the two marker types, congruently revealed that population BY (with relatively high bootstrap values, $72 \%$ and $65 \%$ ), a marginal population from the northwestern part of the natural distribution region, is genetically most distant. Additionally, the relationships among populations were further illustrated by the results of a principal coordinate analysis based on the SSR and STS matrices. The first two coordinates accounted for 30.6 and $25.7 \%$, and 39.4 and $23.3 \%$ of the total variance, respectively (Figs. 3a, 3b). Based on the SSR markers, the difference 
Table II. Number of alleles (in brackets), observed $\left(H_{\mathrm{o}}\right)$ and expected $\left(H_{\mathrm{e}}\right)$ heterozygosity, inbreeding coefficient $\left(F_{\mathrm{IS}}\right)$ at each locus for all populations, and average $H_{\mathrm{e}}$ in each population based on SSR markers.

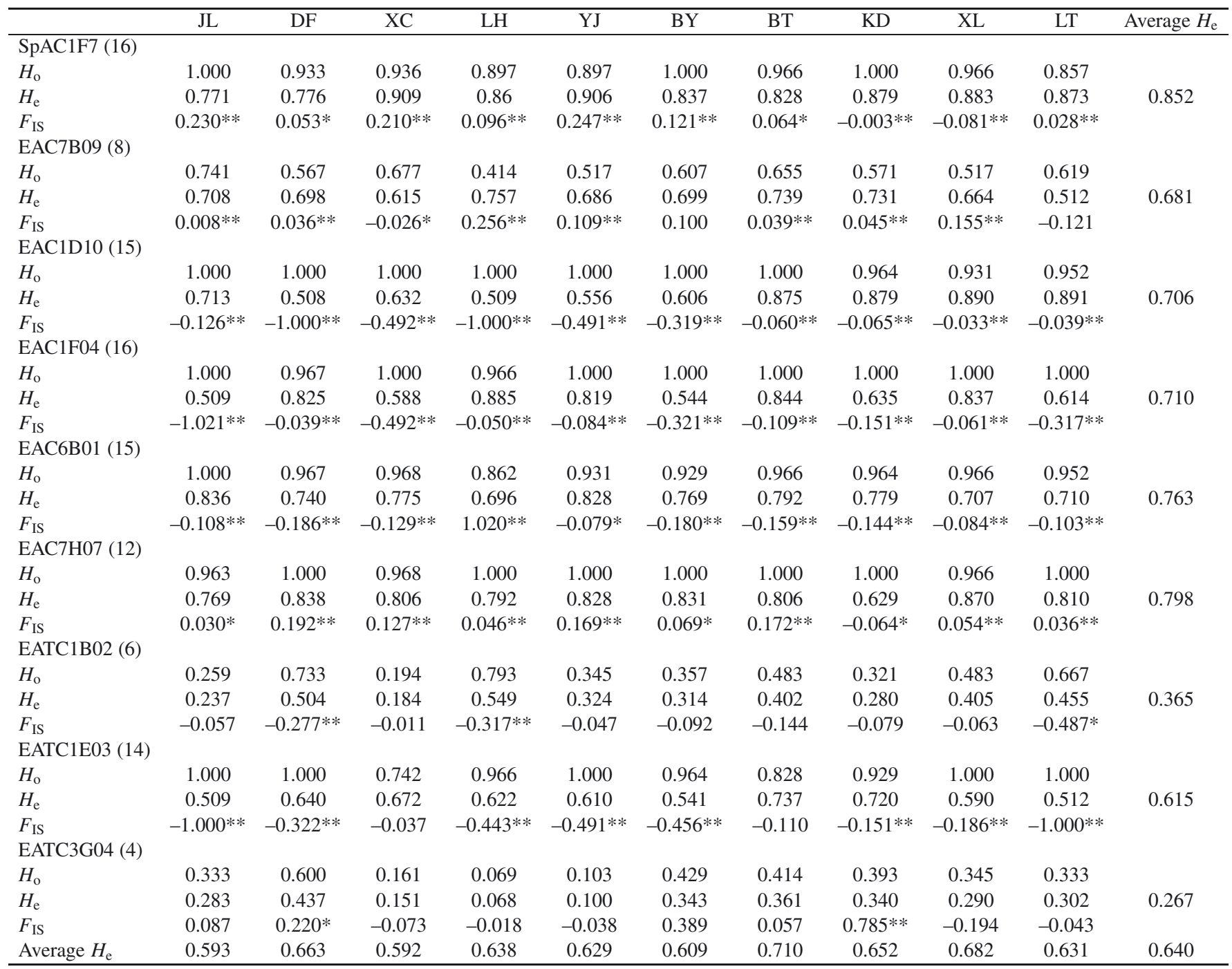

NS: Not significant; ${ }^{*}$ significant at $P<0.05 ;{ }^{* *}$ significant at $P<0.01$.

when compared with the dendrogram was that PCA classified populations BY, DF and YJ as the main cluster. On the other hand, based on the STS markers, PCA classified populations $\mathrm{BY}, \mathrm{XC}, \mathrm{BT}$ and $\mathrm{KD}$ as the main cluster and populations BT and $\mathrm{XC}$ clustered closely but clearly distinctly from the main cluster. Mantel's test showed that there was no significant correlation between genetic distances (measured by $F_{S T}$ ) and the natural logarithm of geographic distances, based on either SSR ( $r=0.104, P=0.255)$ or STS data $(r=0.162, P=0.179)$. A Bayesian cluster analysis revealed that the highest value of $(P / D)$ was at $K=10$ by SSR markers and at $K=8$ by STS markers. The result of the analysis showed that, based on SSR markers, individuals from the same sampling site mostly belong to the same cluster, while, based on the STS markers, individuals from some populations (XL and LH; BT and KD) derive a large part of their genetic composition from another inferred cluster.

\section{DISCUSSION}

The main objective of this study was to assess the level and pattern of genetic variation among $P$. balfouriana populations originating from the southeast of the Qinghai-Tibet Plateau, in order to assist practical conservation actions and resource exploitation of this endemic spruce tree. Compared with previous studies on conifers based on SSR markers, such as investigations on the discontinuously distributed $P$. asperata (mean $H_{\mathrm{e}}=0.707$, Wang et al., 2006) and widely distributed $P$. abies (mean $H_{\mathrm{e}}=0.604$, Meloni et al., 2007; mean $H_{\mathrm{e}}=0.675$, Scotti et al., 2006), P. balfouriana populations possess a moderate degree of genetic diversity (mean $H_{\mathrm{e}}=0.640$ ). Based on STS markers, the variation level of $P$. balfouriana populations was similar to that reported previously for both continuously (mean $H_{\mathrm{e}}=0.573$ ) and disjointedly (mean $H_{\mathrm{e}}=0.566$ ) distributed Sitka spruce populations (Gapare et al., 2005). Thus, 
Table III. Number of alleles (in brackets), observed $\left(H_{\mathrm{o}}\right)$ and expected $\left(H_{\mathrm{e}}\right)$ heterozygosity, inbreeding coefficient $\left(F_{\mathrm{IS}}\right)$ at each locus for all populations, and average $H_{\mathrm{e}}$ in each population based on STS markers.

\begin{tabular}{|c|c|c|c|c|c|c|c|c|c|c|c|}
\hline & $\mathrm{JL}$ & $\overline{D F}$ & $\mathrm{XC}$ & $\mathrm{LH}$ & YJ & $\mathrm{BY}$ & BT & KD & $\mathrm{XL}$ & LT & Average $H_{\mathrm{e}}$ \\
\hline \multicolumn{12}{|l|}{ Sb29 (6) } \\
\hline$H_{\mathrm{o}}$ & 0.259 & 0.767 & 0.484 & 0.724 & 0.379 & 0.929 & 0.621 & 0.429 & 0.828 & 0.619 & \multirow{3}{*}{0.560} \\
\hline$H_{\mathrm{e}}$ & 0.301 & 0.688 & 0.474 & 0.620 & 0.390 & 0.685 & 0.625 & 0.528 & 0.656 & 0.632 & \\
\hline$F_{\text {IS }}$ & 0.136 & -0.014 & 0.044 & Mono & -0.033 & $0.037 * *$ & 0.033 & $0.124 * *$ & -0.208 & -0.06 & \\
\hline \multicolumn{12}{|l|}{ Sb49 (7) } \\
\hline$H_{\mathrm{o}}$ & 0.260 & 0.400 & 0.290 & 0.172 & 0.241 & 0.536 & 0.413 & 0.679 & 0.207 & 0.381 & \multirow{3}{*}{0.381} \\
\hline$H_{\mathrm{e}}$ & 0.477 & 0.341 & 0.290 & 0.164 & 0.276 & 0.464 & 0.622 & 0.670 & 0.194 & 0.316 & \\
\hline$F_{\text {IS }}$ & $0.210 * *$ & -0.110 & -0.035 & -0.030 & 0.066 & $0.077^{*}$ & $0.150 * *$ & $-0.077 * *$ & -0.041 & -0.216 & \\
\hline \multicolumn{12}{|l|}{ Sb21 (10) } \\
\hline$H_{\mathrm{o}}$ & 0.407 & 0.000 & 0.194 & 0.000 & 0.207 & 0.535 & 0.241 & 0.214 & 0.172 & 0.000 & \multirow{3}{*}{0.355} \\
\hline$H_{\mathrm{e}}$ & 0.526 & 0.282 & 0.543 & 0.000 & 0.420 & 0.518 & 0.533 & 0.413 & 0.313 & 0.000 & \\
\hline$F_{\text {IS }}$ & $-0.009 * *$ & $1.000^{* *}$ & $0.572 * *$ & Mono & $0.180 * *$ & $-0.062 *$ & $0.566^{* *}$ & $0.352 * *$ & $0.018 * *$ & Mono & \\
\hline \multicolumn{12}{|l|}{ Sb17 (16) } \\
\hline$H_{\mathrm{o}}$ & 0.889 & 0.833 & 0.871 & 0.931 & 0.897 & 0.929 & 0.828 & 0.929 & 0.966 & 0.905 & \multirow{3}{*}{0.850} \\
\hline$H_{\mathrm{e}}$ & 0.831 & 0.852 & 0.878 & 0.870 & 0.844 & 0.792 & 0.837 & 0.834 & 0.887 & 0.870 & \\
\hline$F_{\text {IS }}$ & $-0.036^{* *}$ & $0.081 * *$ & $0.022 * *$ & $-0.056^{* *}$ & $-0.052 * *$ & $-0.086^{* *}$ & $-0.033^{*}$ & -0.098 & $-0.086 * *$ & $-0.046 * *$ & \\
\hline \multicolumn{12}{|l|}{ Sb62 (8) } \\
\hline$H_{\mathrm{o}}$ & 0.185 & 0.200 & 0.387 & 0.241 & 0.276 & 0.500 & 0.345 & 0.214 & 0.207 & 0.610 & \multirow{3}{*}{0.572} \\
\hline$H_{\mathrm{e}}$ & 0.516 & 0.554 & 0.608 & 0.655 & 0.584 & 0.764 & 0.430 & 0.318 & 0.498 & 0.796 & \\
\hline$F_{\text {IS }}$ & $0.462 * *$ & $0.368 * *$ & $0.116^{* *}$ & $0.486 * *$ & $0.351 * *$ & $0.11 * *$ & $0.302 * *$ & $0.007 * *$ & $0.171 * *$ & $0.011 * *$ & \\
\hline \multicolumn{12}{|l|}{ Sb32 (13) } \\
\hline$H_{\mathrm{o}}$ & 0.296 & 0.167 & 0.419 & 0.483 & 0.310 & 0.214 & 0.621 & 0.679 & 0.517 & 0.286 & \multirow{4}{*}{0.600} \\
\hline$H_{\mathrm{e}}$ & 0.479 & 0.219 & 0.597 & 0.723 & 0.661 & 0.496 & 0.764 & 0.799 & 0.643 & 0.619 & \\
\hline$F_{\text {IS }}$ & $0.019 * *$ & 0.211 & $0.073 * *$ & $0.08 * *$ & $0.248 * *$ & $0.304 * *$ & $0.051 * *$ & $0.032 * *$ & $0.064 * *$ & $0.387 * *$ & \\
\hline Average $H_{\mathrm{e}}$ & 0.522 & 0.489 & 0.565 & 0.505 & 0.529 & 0.620 & 0.635 & 0.594 & 0.532 & 0.539 & \\
\hline
\end{tabular}

NS: Not significant; ${ }^{*}$ significant at $P<0.05 ;{ }^{* *}$ significant at $P<0.01$.

Table IV. Pairwise $F_{\mathrm{ST}}$ values among populations of $P$. balfouriana based on SSR (below) and STS data (above).

\begin{tabular}{|c|c|c|c|c|c|c|c|c|c|c|}
\hline & $\mathrm{JL}$ & $\overline{\mathrm{DF}}$ & $\mathrm{XC}$ & $\mathrm{LH}$ & YJ & $\mathrm{BY}$ & $\overline{\mathrm{BT}}$ & KD & $\mathrm{XL}$ & LT \\
\hline $\mathrm{JL}$ & - & $0.088^{* * *}$ & $0.125^{* * *}$ & $0.117^{* * *}$ & $0.045^{* * *}$ & $0.200^{* * *}$ & $0.081^{* * *}$ & $0.065^{* * *}$ & $0.124^{* * *}$ & $0.094^{* * *}$ \\
\hline DF & $0.138^{* * *}$ & - & $0.172^{* * *}$ & $0.097^{* * *}$ & $0.059^{* * *}$ & $0.217^{* * *}$ & $0.144^{* * *}$ & $0.131^{* * *}$ & $0.143^{* * *}$ & $0.080^{* * *}$ \\
\hline $\mathrm{XC}$ & $0.143^{* * *}$ & $0.166^{* * *}$ & - & $0.197^{* * *}$ & $0.126^{* * *}$ & $0.215^{* * *}$ & $0.148^{* * *}$ & $0.139^{* * *}$ & $0.178^{* * *}$ & $0.152^{* * *}$ \\
\hline LH & $0.116^{* * *}$ & $0.078^{* * *}$ & $0.127^{* * *}$ & - & $0.057^{* * *}$ & $0.109^{* * *}$ & $0.134^{* * *}$ & $0.109^{* * *}$ & $0.029^{* *}$ & $0.086^{* * *}$ \\
\hline YJ & $0.086^{* * *}$ & $0.088^{* * *}$ & $0.169^{* * *}$ & $0.109^{* * *}$ & - & $0.144^{* * *}$ & $0.072^{* * *}$ & $0.064^{* * *}$ & $0.075^{* * *}$ & $0.064^{* * *}$ \\
\hline BY & $0.167^{* * *}$ & $0.197^{* * *}$ & $0.180^{* * *}$ & $0.160^{* * *}$ & $0.137^{* * *}$ & - & $0.136^{* * *}$ & $0.141^{* * *}$ & $0.083^{* * *}$ & $0.128^{* * * *}$ \\
\hline $\mathrm{BT}$ & $0.096^{* * *}$ & $0.090^{* * *}$ & $0.092^{* * *}$ & $0.051^{* * *}$ & $0.075^{* * *}$ & $0.103^{* * *}$ & - & $0.004 \mathrm{NS}$ & $0.098^{* * *}$ & $0.11^{* * *}$ \\
\hline $\mathrm{KD}$ & $0.109^{* * *}$ & $0.118^{* * *}$ & $0.063^{* * *}$ & $0.076^{* * *}$ & $0.127^{* * *}$ & $0.144^{* * *}$ & $0.044^{* * *}$ & - & $0.082^{* * *}$ & $0.104^{* * *}$ \\
\hline XL & $0.124^{* * *}$ & $0.117^{* * *}$ & $0.115^{* * *}$ & $0.096^{* * *}$ & $0.105^{* * *}$ & $0.108^{* * *}$ & $0.052^{* * *}$ & $0.062^{* * *}$ & - & $0.116^{* * *}$ \\
\hline LT & $0.104^{* * *}$ & $0.169^{* * *}$ & $0.123^{* * *}$ & $0.116^{* * *}$ & $0.156^{* * *}$ & $0.175^{* * *}$ & $0.056^{* * *}$ & $0.056^{* * *}$ & $0.080^{* * *}$ & - \\
\hline
\end{tabular}

NS: Not significant; ${ }^{* *}$ significant at $P<0.01{ }^{* * *}$ significant at $P<0.001$.

the $P$. balfouriana populations have similar levels of diversity to other spruce species. Moreover, when we tested the relationship between the genetic diversity of $P$. balfouriana populations and altitude, we found that there was no clear relationship. This result is consistent with studies on other tree species in mountainous regions (Ohsawa, 2008). The result may relate to the complex interaction of ecological and geographical factors in the southeast of the Qinghai-Tibet Plateau. When comparing variation levels, the STS and trinucleotide microsatellite loci showed, on average, a considerably lower diversity level than the dinucleotide microsatellites, both as alleles per locus and as $H_{\mathrm{e}}$ values. This result is likely due to differences in mutation rates (Scotti et al., 2002a).
The amount of genetic diversity varied among the $P$. balfouriana populations. Habitat fragmentation and variable climate conditions may be the main reasons for the uneven distribution of genetic diversity. Population BT possessed the highest level of genetic diversity based on both types of markers. It may be ascribed to the following three causes: (1) Population BT has a large range of tree sizes and a high density. (2) It is located on the eastern bank of the middle reaches of the Jinsha River, where it can easily exchange genetic material with other populations by seed or pollen dispersal. (3) Introgression from another species is also a possible reason since hybridization commonly occurs between many Picea species. Other spruce species, such as P. likiangensis, occur in 


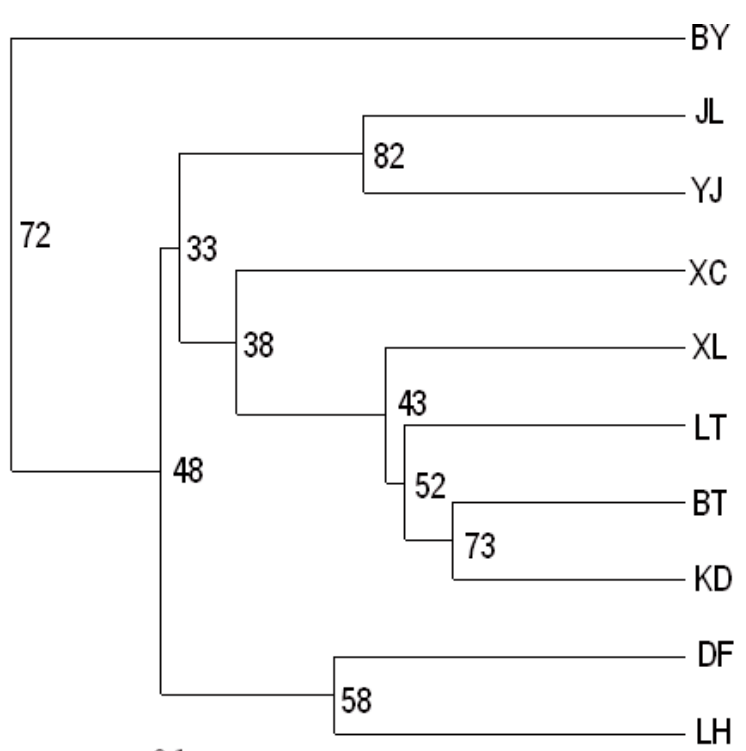

(a)

0.1

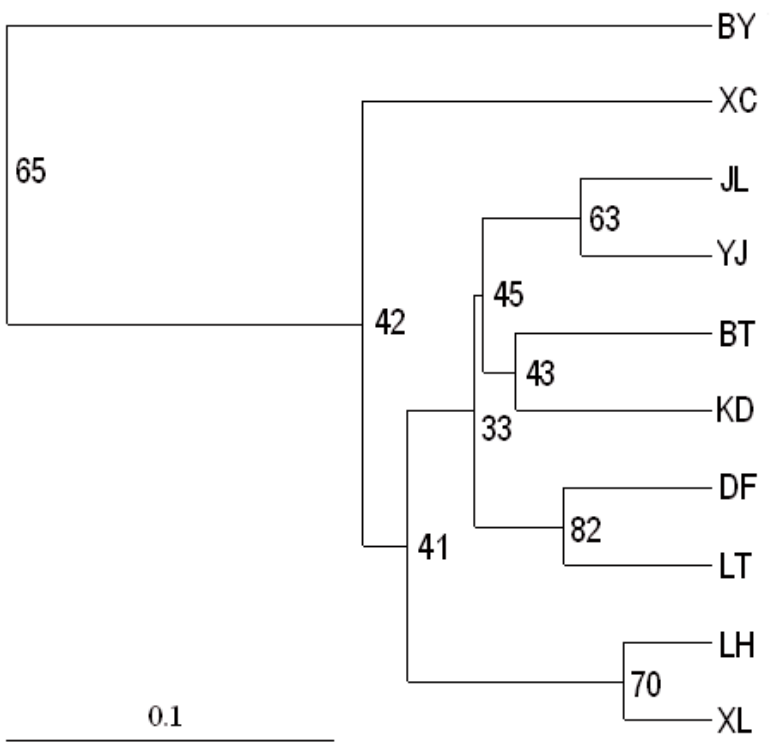

Figure 2. The dendrograms of $P$. balfouriana revealed by UPGMA cluster analysis based on Nei's (1972) standard genetic distances and bootstrapped across loci (1 000 replicates). UPGMA cluster analysis: (a) based on nine SSR markers; (b) based on six STS markers.

neighboring geographical regions of population BT. Thus, hybridization between species may happen in the overlapping region of distribution, as detected for some other Chinese conifer species as well (Luo et al., 2005; Szmidt and Wang, 1993).

When comparing the SSR and STS data sets, the inbreeding coefficients $F_{\text {IS }}$ were not of the same order of magnitude for these two types of markers. The SSR markers showed that the whole set of populations did not deviate from the Hardy-Weinberg equilibrium $\left(F_{\text {IS }}=-0.030\right)$, while the STS markers indicated a considerable deficiency of heterozygosity
$\left(F_{\mathrm{IS}}=0.249\right)$. A possible explanation for such a contradictory result is the different technical resolution capacity of the two types of markers. SSR markers represent repeat sequences which are usually outside gene coding regions and have high mutation rates, and thus, they are generally considered neutral. On the other hand, STS markers, which are derived from arbitrarily selected genes, are not adaptively neutral, and, accordingly, the STS loci may have lower mutation rates than the SSR loci. High levels of inbreeding have also been detected in some other coniferous tree species, e.g., P. sitchensis (Gapare et al., 2005), P. asperata (Wang et al., 2006) and $P i$ nus contorta (Thomas et al., 1999), which may be related to population size or habitat fragmentation. In addition, the presence of null alleles may contribute to heterozygote deficiency, as detected especially by STS markers.

Both marker types showed that most genetic diversity existed within populations. Compared with previous studies, the amount of genetic differentiation of $P$. balfouriana was lower than that of $P$. asperata, which is distributed narrowly and discontinuously (Wang et al., 2006), but distinctly higher than the values detected among populations of widespread Norway spruce (Maghuly et al., 2006; Meloni et al., 2007), transcontinentally distributed black spruce (Perry and Bousquet, 2001) and both disjointedly and continuously distributed Sitka spruce (Gapare et al., 2005). Moreover, high levels of population differentiation have been commonly observed in plant species from the southeast of the Qinghai-Tibet Plateau when compared with other species belonging to the same genus, e.g., Cupressus gigantean (Xia et al., 2008), P. asperata (Wang et al., 2006), Gentiana atuntsiensis and G. striolata (Zhang et al., 2007), Megacodon stylophorus (Ge et al., 2005) and Populus cathayana (Lu et al., 2006; Peng et al., 2005). Habitat fragmentation in the southeast of the QinghaiTibet Plateau may account for the relatively high levels of $F_{\text {ST }}$ values. On one hand, fragmented habitats in regions with complex topography may limit pollen exchange and seed dispersal among populations, while on the other hand, variable climate with different temperature regimes among the discontinuous and patchy $P$. balfouriana populations can postpone or advance flower development and, further, cause asynchronous flowering periods among populations. Therefore, the phenological gap may also contribute to the observed differentiation.

Bayesian analyses can be used to both assess the genetic structure of populations and infer possible populations of provenance for the studied populations or individuals (Bertorelle and Excoffier, 1998; Meloni, 2007; Pritchard et al., 2000). In this study, Bayesian assignment analysis assigned individuals of the same sampling site mostly to the same cluster, especially based on SSR markers, although the presence of gene flow was evident among some populations. The results of the structure analysis also proved that the majority of P. balfouriana populations in the southeast of the QinghaiTibet Plateau show a mosaic-like pattern and a high degree of differentiation among populations.

The correlation between Nei's (1972) pairwise standard genetic distances between populations based on the two types of markers was significant $(r=0.40, P<0.05)$. The UPGMA clustering analyses and PCA plot similarly showed 

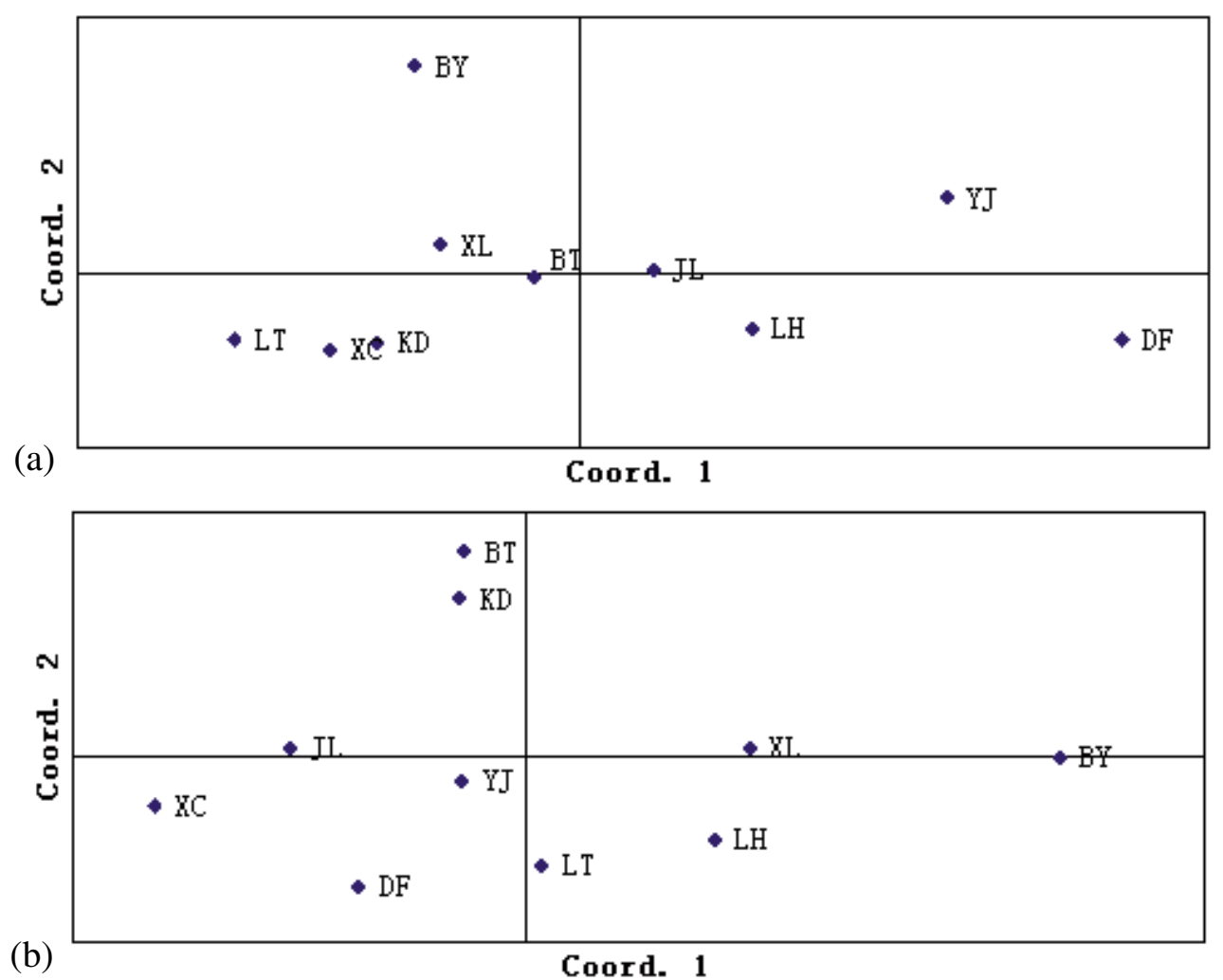

Figure 3. The PCA plot of coordinates via a covariance matrix with data standardization based on pairwise Nei genetic distances. PCA plot of coordinates: (a) based on nine SSR markers; (b) based on six STS markers.

that population BY differed from other populations based on both kinds of markers. Population BY, located in the northwestern section of the Hengduan Mountains, is embraced by the Saluli Mountain in the eastern, Magongga Mountain in the southern and Jinsha River in the western direction, and thus it is isolated from other P. balfouriana populations. Mountains form barriers and play an important role in preventing gene exchange between population BY and other populations, which consequently leads to great divergence.

In summary, the results obtained in this study revealed that: (1) a moderate degree of genetic variation is present in $P$. balfouriana in the southeast of the Qinghai-Tibet Plateau. (2) Considerable population differentiation exists among the ten P. balfouriana populations based on both SSR and STS markers, possibly caused by habitat fragmentation and heterogeneous environments. (3) The result of the Bayesian assignment analyses demonstrated that individuals from the same sampling site mostly belong to the same cluster, but they also showed the presence of gene flow among some populations. (4) The UPGMA clustering and PCA analyses congruously separated population BY from other populations, which is likely due to the presence of mountain barriers. A priority in conservation biology is to preserve genetic variation in order to promote species survival (Allendorf and Leary, 1986). Thus, enhancing gene exchange should be taken into account in the conservation management strategies of $P$. balfouriana in the southeast of the Qinghai-Tibet Plateau, e.g., crossings, seed exchange and transplantation between populations. So far, although $P$. balfouriana is used as a prime reforestation species in its region of distribution, the available knowledge of its ecological, physiological and genetic features has been limited. Further advanced research on $P$. balfouriana, especially investigations of eco-physiological parameters, and of demographic and genetic population structures, will facilitate advanced conservation actions and improvement strategies in P. balfouriana.

Acknowledgements: The research was supported by the Young Scholars Program of the National Science Foundation of China (No. 30600480), Light Foundation of the Chinese Academy of Sciences and Foundation of the President of the Chinese Academy of Sciences.

\section{REFERENCES}

Acheré V., Faivre R.P., Jeandroz S., Besnard G., Markussen T., Aragones A., Fladung M., Ritter E., and Favre J.M., 2004. A full saturated linkage map of Picea abies including AFLP, SSR, ESTP, 5S rDNA and morphological markers. Theor. Appl. Genet. 108: 1602-1613.

Allendorf F.W. and Leary R.F., 1986. Heterozygosity and fitness in natural populations of animals. Conservation Biology. In: Soule M.E. (Ed.), Sunderland, MA: Sinauer, the science of scarcity and diversity, pp. 57-76.

Bertorelle G. and Excoffier L., 1998. Inferring admixture proportions from molecular data. Mol. Biol. Evol. 15: 1298-1311. 
Bouillé M. and Bousquet J., 2005. Trans-species shared polymorphisms at orthologous nuclear gene loci among distant species in the conifer Picea (Pinaceae): implications for the long-term maintenance of genetic diversity in trees. Am. J. Bot. 92: 63-73.

Brookfield J.F.Y., 1996. A simple new method for estimating null allele frequency from heterozygote deficiency. Mol. Ecol. 5: 453-455.

Collaborating Group for Vegetation of Sichuan, 1980. Vegetation of Sichuan. Sichuan People's press, Chengdu, pp. 159-162 (in Chinese).

ECCAS (Editor Committee of the Chinese Academy of Sciences for Flora of China), 1978. Flora of China Vol. 7, science press, Beijing, pp. 153-155 (in Chinese).

Editorial Committee of the Sichuan Flora, 1983. Flora Sichuanica Vol. 2, Sichuan people's press, Chengdu, pp. 77-79 (in Chinese).

Editorial Committee of Forest of China, 1999. Forest of China Vol. 2. China forestry publishing house, Beijing, pp. 731-743 (in Chinese).

Evanno G., Regnaut S., and Goudet J., 2005. Detecting the number of clusters of individuals using the software Structure: a simulation study. Mol. Ecol. 14: 2611-2620.

Excoffier L., Laval G., and Schneider S., 2005. Arlequin (version 3.0): an integrated software package for population genetics data analysis. Evol. Bioinform. Online 1: 47-50.

Falush D., Stephens M., and Pritchard J.K., 2003. Inference of population structure using multilocus genotype data: linked loci and correlated allele frequencies. Genetics 164: 1567-1587.

Gapare W.J., Aitken S.N., and Ritland C.E., 2005. Genetic diversity of core and peripheral Sitka spruce (Picea sitchensis (Bong.) Carr) populations: implications for conservation of widespread species. Biol. Conserv. 123: 113-123.

Ge X.J., Zhang Y.M., Hao G., and Chiang T.Y., 2005. Strong genetic differentiation of the East-Himalayan Megacodon stylophorus (Gentianaceae) detected by Inter-Simple Sequence Repeats (ISSR). Biodivers. Conserv. 14: 849-861.

Goudet J., 2001. FSTAT, A Program to Estimate and test gene diversities and fixation indices version 2.9.3. Available at: www.unil.ch/izea/ softwares/fstat.html.

Guo S.W. and Thompson E.A., 1992. Performing the exact test of HardyWeinberg proportions for multiple alleles. Biometrics 48: 361-372.

Hochberg Y., 1988. A sharper Bonferroni procedure for multiple tests of significance. Biometrika 75: 800-802.

Li Y.C., Korol A.B., Fahima T., Beiles A., and Nevo E., 2002. Microsatellites: genomic distribution, putative functions, and mutational mechanisms: a review. Mol. Ecol. 11: 2453-2465.

Liu J.M., Wang L., Geng Y.P., Wang Q.B., Luo L.J., and Zhong Y., 2006. Genetic diversity and population structure of Lamiophlomis rotata (Lamiaceae), an endemic species of Qinghai-Tibet Plateau. Genetica 128: 385-394.

Liu Z.L., Fang J.Y., and Piao S.L., 2002. Geographical distribution of species in genera Abies, Picea and Larix in china. Acta Geogr. Sin. 57: $577-589$.

Lu Z.X., Wang Y.H., Peng Y.H., Korpelainen H., and Li C.Y., 2005. Genetic diversity of Populus cathayana Rehd populations in southwestern China revealed by ISSR markers. Plant Sci. 170: 407-412.

Luo J.X., Wang Y.H., Korpelainen H., and Li C.Y., 2005. Allozyme variation in natural populations of Picea asperata. Silva Fenn. 39: $167-176$

Maghuly F., Pinsker W., Praznik W., and Fluch S., 2006. Genetic diversity in managed subpopulations of Norway spruce [Picea abies (L.) Karst.]. For. Ecol. Manage. 222: 266-271.
Mantel N., 1967. The detection of disease clustering and a generalized regression approach. Cancer Res. 27: 209-220.

Meloni M., Perini D., and Binelli G., 2007. The distribution of genetic variation in Norway spruce (Picea abies Karst.) populations in the western Alps. J. Biogeogr. 34: 929-938.

Myers N., Mittermeier R.A., Mittermeier C.G., da Fonseca G.A.B., and Kent J., 2000. Biodiversity hotspots for conservation priorities. Nature 403: 853-858.

Nei M., 1972. Genetic distance between populations. Am. Nat. 106: 283-292.

Olivier L., 2002. Populations 1.2.28. Available at: http://bioinformatics. org/ tryphon/populations/.

Oliveira E.J., Pádua J.G., Zucchi M.I., Vencovsky R., and Vieira M.L.C., 2006. Origin, evolution and genome distribution of microsatellites. Genet. Mol. Biol. 29: 294-307.

Ohsawa T., Saito Y., Sawada H., and Ide Y., 2008. Impact of altitude and topography on the genetic diversity of Quercus serrata populations in the Chichibu Mountains, central Japan. Flora 203: 187-196.

Page R.D.M., 1996. TREEVIEW: An application to display phylogenetic trees on personal computers. Comput. Appl. Biosci. 12: 357-358.

Panaud O., Chen X., and McCouch S.D., 1996. Development of microsatellite markers and characterization of sample sequence lengthen polymorphism (SSLP) in rice (Oryzastiva L.). Mol. Gen. Genet. 252: 597-607.

Peakall R. and Smouse P.E., 2006. GenAlEx 6: genetic analysis in Excel. Population genetic software for teaching and research. Mol. Ecol. Notes 6: 288-295.

Pelgas B., Beauseigle S., Acheré V., Jeandroz S., Bousquet J., and Isabel N., 2006. Comparative genome mapping among Picea glauca, $P$. mariana $\times P$. rubens and $P$. abies, and correspondence with other Pinaceae. 113: 1371-1393.

Peng Y.H., Lu Z.X., Chen K., Luukanen O., Korpelainen H., and Li C.Y., 2005. Population genetic survey of Populus cathayana originating from Southeastern Qinghai-Tibetan plateau of China based on SSR markers. Silvae Genet. 54: 116-122.

Perry D.J. and Bousquet J., 1998a. Sequence-tagged-site (STS) markers of arbitrary genes: development, characterization and analysis of linkage in black spruce. Genetics 149: 1089-1098.

Perry D.J. and Bousquet J., 1998b. Sequence-tagged-site (STS) markers of arbitrary genes: the utility of black spruce-derived STS primers in other conifers. Theor. Appl. Genet. 97: 735-743.

Perry D.J. and Bousquet J., 2001. Genetic diversity and mating system of post-fire and post-harvest black spruce: an investigation using codominant sequence-tagged-site (STS) markers. Can. J. For. Res. 31: $32-40$

Pfeiffer A., Olivieri A.M., and Morgante M., 1997. Identification and characterization of microsatellites in Norway spruce (Picea abies K.). Genome 40: 411-419.

Pritchard J.K., Stephens M., and Donnelly P., 2000. Inference of population structure using multilocus genotype data. Genetics 155: 945-959.

Rajora O.P., Rahman M.H., Buchert G.P., and Dancik B.P., 2000. Microsatellite DNA analysis of genetic effects of harvesting in oldgrowth eastern white pine (Pinus strobes) Ontario, Canada. Mol. Ecol. 9: 339-348.

Raymond M. and Rousset F., 1995. GENEPOP (version 1.2): population genetics software for exact tests and ecumenicism. J. Hered. 86: 248-249.

Rice W.R., 1989. Analyzing tables of statistical tests. Evolution 43: $223-225$. 
Scotti I., Magni F., Paglia G.P., and Morgante M., 2002a. Trinucleotide microsatellites in Norway spruce (Picea abies): their features and the development of molecular markers. Theor. Appl. Genet. 106: 40-50.

Scotti I., Paglia G.P., Magni F., and Morgante M., 2002b. Efficient development of dinucleotide microsatellite markers in Norway spruce (Picea abies Karst.) through dot-blot selection. Theor. Appl. Genet. 104: 1035-1041.

Scotti I., Paglia G.P., Magni F., and Morgante M., 2006. Population genetics of Norway spruce (Picea abies Karst.) at regional scale: sensitivity of different microsatellite motif classes in detecting differentian. Ann. For. Sci. 63: 485-491.

Selkoe K.A. and Toonen R.J., 2006. Microsatellites for ecologists: a practical guide to using and evaluating microsatellite markers. Ecol. Lett. 9: 615-629.

Szmidt A.Z. and Wang X.R., 1993. Molecular systematics and genetic differentiation of Pinus sylvestris (L.) and P. densiflora (Sieb. et Zucc.). Theor. Appl. Genet. 86: 159-165.

Thomas B.R., Macdonald S.E., Hicks M., Adams D.L., and Hodgetts R.B., 1999. Effects of reforestation methods on genetic diversity of lodgepole pine: an assessment using microsatellite and randomly amplified polymorphic DNA markers. Theor. Appl. Genet. 98: 793-801.

Wang Y.H., Korpelainen H., and Li C.Y., 2006. Microsatellite polymorphism in the edaphic spruce, Picea asperata, originating from the mountains of China. Silva Fenn. 40: 561-575.
Weir B.S. and Cockerham C.C., 1984. Estimating $F$-statistics for the analysis of population structure. Evolution 38: 1358-1370.

Wright S., 1969. Evolution and genetics of populations. Vol. 2, The theory of gene frequencies, Chicago, University of Chicago Press.

Xia T., Meng L., Mao K., Tian B., Miehe G., and Liu J., 2008. Genetic variation in the Qinghai-Tibetan plateau endemic and endangered conifer Cupressus gigantea, detected using RAPD and ISSR markers. Silvae Genet. 57: 85-92.

Ying T.S., 1989. Areography of the gynmosperms of China (1) - distribution of the Pinaceae of China. Acta Phytotaxonomica Sinica 27: $27-38$

Yuan R.J., Wang B.R., and Yang S.H., 2007. Comparative study on Picea and Abies in Hengduan mountainous areas. Journal of West China Forestry Science 36:16-21.

Zhang Q., Chiang T.Y., George M., Liu J.Q., and Abbott R.J., 2005. Phylogeography of the Qinghai-Tibetan Plateau endemic Juniperus przewalskii (Cupressaceae) inferred from chloroplast DNA sequence variation. Mol. Ecol. 14: 3513-3524.

Zhang X.L., Yuan Y.M., and Ge X.J., 2007. Genetic structure and differentiation of Gentiana atuntsiensis. In: W.W. Smith and G.S.T.N. Ho (Eds), (Gentianaceae) as revealed by ISSR markers. Bot. J. Linn. Soc. 154: 225-232. 